\title{
ANALISIS KELIMPAHAN, KOMPOSISI DAN SUMBER SAMPAH LAUT: STUDI KASUS PADA PANTAI KUALA BATU DESA PULAU KAYU KABUPATEN ACEH BARAT DAYA
}

\section{THE ANALYSIS OF MARINE DEBRIS ABUNDANCE, COMPOSITION AND SOURCES: A CASE STUDY IN KUALA BATU BEACH, PULAU KAYU VILLAGE, ACEH BARAT DAYA REGENCY}

\author{
Fitria Rahmayanti ${ }^{1}$, Farah Diana ${ }^{1}$, Nurul Najmi ${ }^{2}$, Etty Riani ${ }^{3}$, Gatot Yulianto ${ }^{3}$, Munandar ${ }^{4}$ \\ ${ }^{1}$ Prodi Akuakultur Fakultas Perikanan dan Ilmu Kelautan, Universitas Teuku Umar Jalan Alue Peunyareng, \\ Meulaboh, Aceh Barat 23615, Aceh, Indonesia. \\ ${ }^{2}$ Prodi Sumber Daya Akuatik, Universitas Teuku Umar Jalan Alue Peunyareng, Meulaboh, Aceh Barat \\ 23615, Aceh, Indonesia. \\ ${ }^{3}$ Departemen Manajemen Sumberdaya Perairan, Fakultas Perikanan dan Ilmu Kelautan, Institut Pertanian \\ Bogor, Bogor, Jawa Barat, Indonesia. \\ ${ }^{4}$ Program Studi Ilmu Kelautan, Universitas Teuku Umar Jalan Alue Peunyareng, Meulaboh, Aceh Barat \\ 23615, Aceh, Indonesia.
}

Korespondensi: fitriarahmayanti@utu.ac.id

\begin{abstract}
ABSTRAK
Sampah laut telah menjadi masalah dan ancaman bagi ekosistem, keanekaragaman hayati maupun kehidupan laut. Oleh sebab itu, diperlukan kebijakan, strategi mitigasi dan rencana aksi yang tepat untuk mengatasi masalah tersebut. Tujuan Penelitian ini adalah untuk mendapatkan gambaran tentang jumlah, komposisi dan sumber sampah laut yang nantinya dapat dijadikan referensi untuk mengatasi masalah sampah laut. Penelitian ini dilaksanakan di Pantai Kuala Batu, Desa Pulau Kayu Kabupaten Aceh Barat Daya. Metode pengumpulan sampel ditetapkan berdasarkan protokol penelitian oleh NOAA Marine Debris Shoreline Survey Field Guide (2012). Hasil penelitian ini menunjukkan bahwa jumlah sampah laut yang terkumpul selama penelitian adalah $232 \mathrm{item} / 1.200 \mathrm{~m}^{2}$ dan densitasnya $0.193 \mathrm{item} / \mathrm{m}^{2}$. Sampah plastik merupakan jenis sampah laut dengan jumlah tertinggi yaitu $79 \%$ dan sumber sampah laut tertinggi di pantai ini berasal dari daratan (land-based sourced) melalui kegiatan rekreasi dan aktivitas pantai yaitu $79 \%$.
\end{abstract}

Kata kunci : polusi, pencemaran, plastik, lingkungan, ekosistem

ABSTRACT

Marine debris is a serious problem that is threatening marine ecosystem, biodiversity and marine life. Therefore, the proper policies, mitigation strategies and action plans are needed to resolve these problems. The objective of this study were to get the information about the abundance, composition and sources of marine debris as a reference to resolve marine debris problem. This research was conducted at Kuala Batu Beach, Pulau Kayu Village, Aceh Barat Daya Regency. The sample collections method was designed based on the research protocol by NOAA Marine Debris Shoreline Survey Field Guide (2012). The results of this study indicate that the abundance of marine debris during the study were 232 items $/ 1,200 \mathrm{~m}^{2}$ and its density was $0.193 \mathrm{item} / \mathrm{m}^{2}$. Plastic was the highest of marine debris accounted which is $79 \%$ and landbased sourced through recreational activities and beach activities was the highest source of marine debris in this beach which is $79 \%$.

Keywords : pollution, contamination, plastic, environment, ecosytem. 


\section{PENDAHULUAN}

Penggunaan plastik dalam kehidupan manusia terus meningkat, hal ini mengakibatkan produksi plastik di dunia mengalami peningkatan setiap tahunnya. Jambeck et al. (2015) menyatakan bahwa Indonesia menduduki urutan kedua setelah China sebagai negara penyumbang sampah laut di dunia dengan estimasi jumlah sampah yang dihasilkan adalah 0.48 - 1.29 juta ton per tahun. Ondara dan Ruzana (2020) melaporkan bahwa kota Banda Aceh sebagai ibukota Propinsi Aceh menghasilkan 20 ton sampah setiap harinya dan hanya sekitar 12 ton yang dapat didaur ulang.

Menurut Opfer et al. (2012), Sumber sampah laut dapat diklasifikasikan ke dalam kelompok sampah laut yang berasal dari lautan (ocean-based souces) dan sampah laut yang berasal dari daratan (land-based sources) dengan kategori bahan termasuk logam, plastik, karet, kaca, kain, kertas/kayu olahan, dan yang tidak dapat diklasifikasikan (tidak dikenal). Setidaknya terdapat tiga dampak yang diakibatkan oleh sampah laut, yaitu berefek pada kesehatan dan kehidupan manusia, merusak ekosistem laut dan mengancam kehidupan organisme bawah laut (FAO, 2017; Opfer et al., 2012 dan Rochman et al., 2015). Menurut Pawar et al. (2016), sampah laut berdampak pada kesehatan dan keselamatan manusia, degradasi habitat dan ekosistem, mengganggu sektor perikanan dan pariwisata, serta mengganggu navigasi.

Shuker et al. (2018) telah mengklaim bahwa "Indonesia adalah negara dengan kekayaan laut yang sangat tinggi atau disebut "megadiverse". Ini tersebar hingga ke tiga wilayah geografis dan memiliki tempat yang sangat baik untuk menumbuhkan lebih dari 76 persen spesies karang, hutan bakau yang luas, dan padang lamun. Namun, deforestasi pantai, penurunan kualitas air, dan polusi telah berdampak parah pada ekosistem ini. Ekosistem laut Indonesia berada dalam bahaya besar karena menghasilkan limbah yang konstan. Melalui urbanisasi dan pertumbuhan populasi pesisir yang cepat, tingkat polusi yang masuk dan menghancurkan ekosistem ini juga akan meningkat; semakin memperburuk situasi saat ini”.

Laut merupakan salah satu ekosistem yang paling besar mengalami kerusakan sebagai dampak buruk dari kehadiran sampah laut, terutama yang berbahan plastik. Oleh sebab itu, polusi laut yang disebabkan oleh sampah plastik menjadi isu yang sangat menarik dan penting untuk dikaji lebih lanjut. Aceh merupakan salah satu provinsi di Indonesia, dengan garis pantai yang panjang sehingga memiliki resiko serius terhadap masalah lingkungan yang disebabkan oleh sampah laut. Sebagai langkah awal untuk mendapatkan data yang valid tentang gambaran 
jumlah, komposisi dan sumber sampah laut, maka kami melaksanakan penelitian di Pantai Kuala Batu, Desa Pulau Kayu, Kabupaten Aceh Barat Daya. Hasil penelitian ini menyajikan data tentang kelimpahan, komposisi dan sumber sampah laut yang nantinya dapat dijadikan sebagai referensi kebijakan pemerintah, strategi mitigasi dan rencana aksi yang diperlukan untuk menyelesaikan masalah sampah laut di Aceh.

\section{METODE PENELITIAN}

\section{Waktu dan Lokasi}

Penelitian ini dilaksanakan di Pantai Kuala Batu yang berlokasi di Desa Pulau Kayu Kabupaten Aceh Barat Daya (Gambar 1.) pada bulan Mei 2019. Penentuan titik pengumpulan sampel mengikuti protokol pelaksanaan penelitian Standing-Stock Surveys yang ditetapkan oleh NOAA Marine Debris Shoreline Survey Field Guide (Opfer et al., 2012).

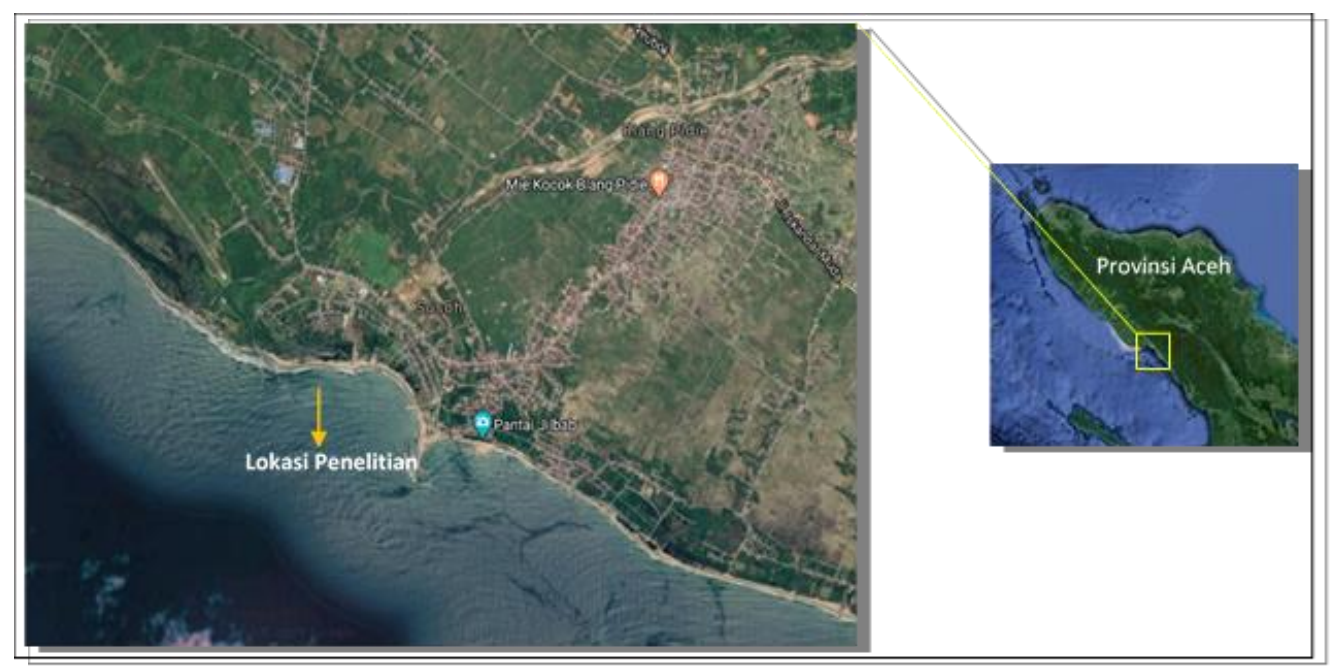

Gambar 1. Peta lokasi penelitian

Pada lokasi penelitian dilakukan pengukuran pantai sepanjang 100 meter yang kemudian dibagi masing-masing 5 meter sehingga didapatkan total 20 bagian. Setiap bagian diukur dari tepi air surut terendah hingga menuju 60 meter ke belakang garis pantai (dapat dilihat pada Gambar. 2). Pengukuran Selanjutnya, dilakukan pemilihan empat titik survei dari total 20 bagian secara acak. Pengukuran dilakukan secara tegak lurus dengan menggunakan transek garis. Untuk garis pantai yang tidak lurus, maka masing-masing titik yang telah dipilih akan diukur 
panjangnya dimulai dari tepi air surut terendah menuju belakang garis pantai sepanjang 60 meter secara tegak lurus. Penelitian ini dilaksanakan bertepatan pada musim angin timur (angin muson timur), dimana cuaca selama penelitian sangat cerah.

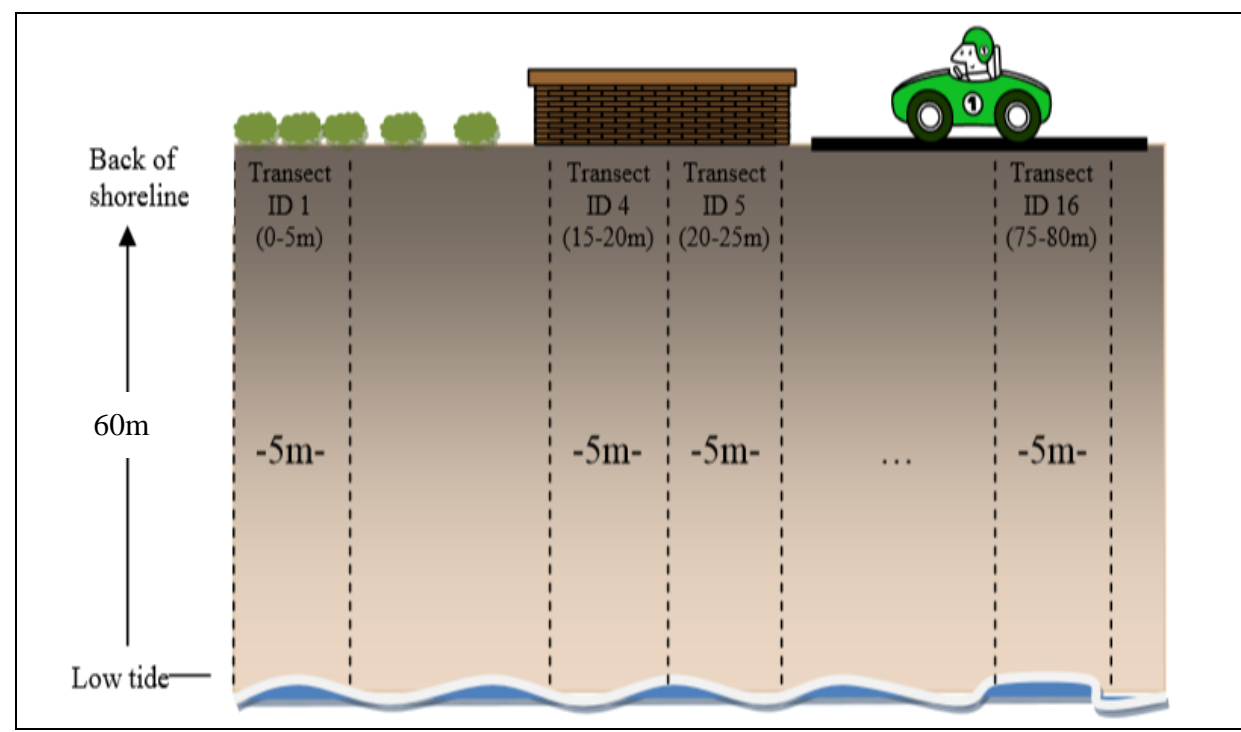

Gambar 2. Pembagian garis pantai (100 m) transek tegak lurus (Opfer et al., 2012)

\section{Pengumpulan Data}

Data sampah laut dikumpulkan dengan cara menyusuri masing-masing titik yang telah ditentukan dengan mengikuti skema potential survey walking patterns yang telah ditetapkan oleh NOAA Marine Debris Shoreline Survey Field Guide (Opfer et al., 2012) untuk memastikan bahwa seluruh lokasi garis pantai atau transek tercakup. Jarak yang disarankan antara jalur berjalan adalah sekitar satu meter (Gambar 3.). Sampah yang ditemukan kemudian dicatat pada lembar kerja dengan dilakukan pengelompokan berdasarkan karakter jenis sampah berdasarkan klasifikasi oleh NOAA Marine Debris Shoreline Survey Field Guide (Opfer et al., 2012). Data sampah yang dicatat hanya sampah yang ditemukan di walking pattern, sampah yang berada diluarnya tidak dicatat pada form lembar kerja. 


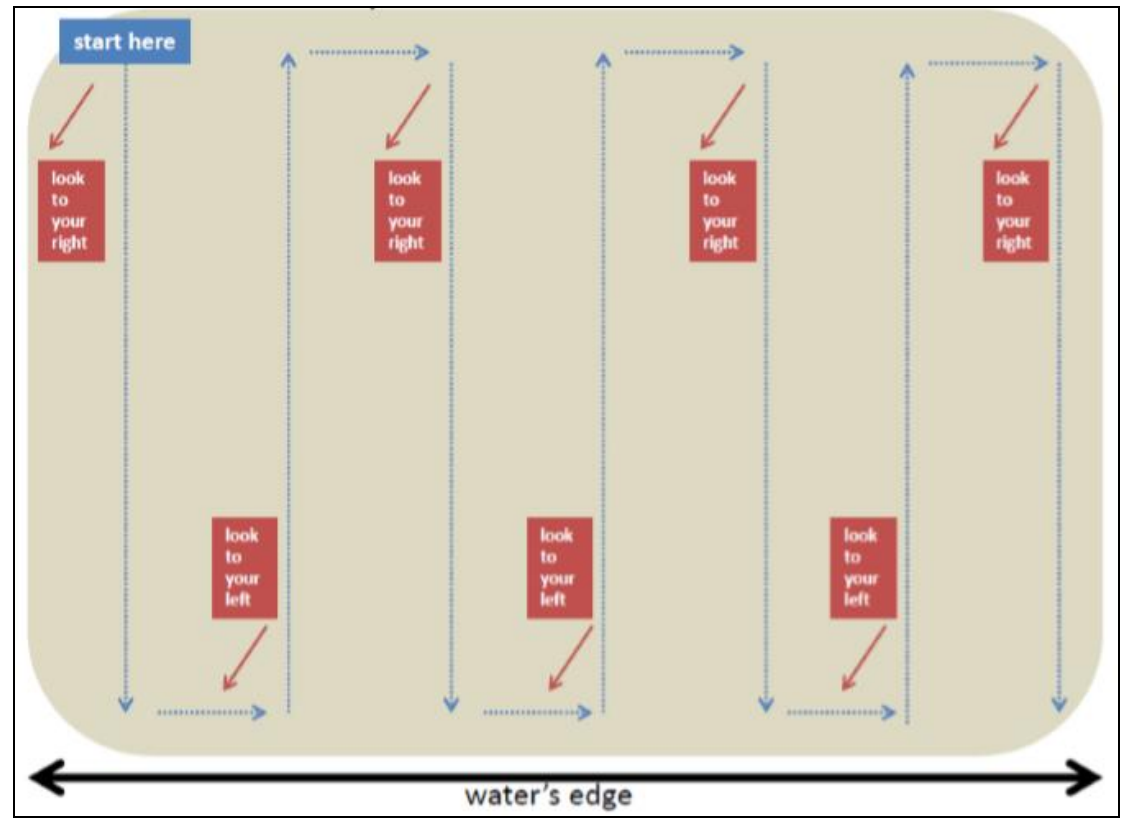

Gambar 3. Skema berjalan/Walking pattern (Opfer et al., 2012)

\section{Analisis Data}

Kelimpahan sampah laut didapatkan dari total sampah yang ditemukan selama penelitian berlangsung. Kemudian dilakukan perhitungan densitas atau kepadatan sampah laut dengan menggunakan rumus berikut:

$$
\text { Densitas sampah laut }=\frac{\text { Total sampah laut dari empat titik survei }}{\text { Total luas keempat titik survei }}
$$

Komposisi sampah laut diklasifikasikan kedalam tujuh kelompok yaitu (1) plastik, (2) logam atau metal, (3) kaca, (4) karet, (5) kertas dan turunannya, (6) kain dan turunannya, (7) lain-lain/tidak dapat diklasifikasikan. Selanjutnya, untuk sumber dari sampah laut, dilakukan pengelompokan kedalam enam kelompok (The Ocean Conservacy, 2010) yaitu (1) rekreasi dan aktivitas pantai, (2) aktivitas merokok dan sejenisnya, (3) aktivitas pembuangan, (4) medis/personal hygiene, (5) aktivitas laut/jalur laut, dan (6) lain-lain. Hasil yang didapat akan dianalisis secara statistik deskriptif. 


\section{HASIL DAN PEMBAHASAN}

\section{Kelimpahan dan Densitas Sampah Laut}

Jumlah sampah laut yang berhasil dikumpulkan selama penelitian berjumlah 232 item $/ 1.200 \mathrm{~m}^{2}$ dengan densitas sampah laut yaitu $0.193 \mathrm{item} / \mathrm{m}^{2}$. Menurut Law et al. (2010), sampah laut merupakan masalah lingkungan yang muncul secara global dan tercatat lebih dari 580.000 item sampah per kilometer persegi ditemukan di laut lepas. Distribusi sampah secara spasial dan akumulasi sampah laut dipengaruhi oleh beberapa faktor seperti hidrografi, geomorfologi (Barnes et al., 2009) serta angin dan kegiatan antropogenik (Ramirez et al., 2013). Selain itu, keberadaan sampah laut juga disebabkan karena adanya aktivitas rekreasi dan industri dekat pantai (Hardesty et al., 2016).

Pantai Kuala Batu terletak dekat dengan daerah pemukiman yang padat penduduk. Selain itu, pantai ini juga berdekatan dengan muara sungai yang aliran airnya melewati pemukiman padat penduduk. Selama penelitian berlangsung, banyak ditemukan sampah-sampah yang terbawa oleh aliran sungai kemudian maenuju ke muara dan akhirnya masuk ke laut. Pantai ini juga berdekatan dengan pusat rekreasi, dimana kafe-kafe setempat tidak mengelola sampahnya dengan baik. Hal-hal tersebut diprediksi menjadi salah satu penyebab banyaknya sampah di sepanjang Pantai Kuala Batu.

Menurut Corcoran et al. (2009), pusat akumulasi sampah laut terdapat pada pantai yang letaknya dekat dengan pemukiman padat penduduk. Selanjutnya, hasil penelitian yang dilakukan oleh Fitria et al. (2019) di beberapa pantai yang terletak di pantai barat-selatan Aceh, menunjukkan bahwa jumlah sampah laut tertinggi ditemukan di pantai dengan kepadatan penduduk yang tinggi, daerah pantai rekreasi dan pantai yang dekat dengan pelabuhan perikanan.

\section{Komposisi Sampah Laut}

Plastik merupakan jenis sampah laut yang paling banyak ditemukan di Pantai Kuala Batu yaitu sebanyak 79\% dari total sampah laut. Kemudian diikuti oleh jenis karet (7.4\%), lainlain/tidak dapat diklasifikasikan (6.3\%), kaca (3.6\%), logam/metal (2.3\%), kertas/turunannya $(0.7 \%)$ dan kain/turunannya $(0.7 \%)$. Hasil penelitian yang dilakukan oleh berbagai peneliti menunjukkan bahwa plastik merupakan jenis sampah laut yang paling tinggi jumlahnya ditemukan di berbagai wilayah, seperti di Kepulauan Seribu, Jakarta (Assuyuti et al., 2018), 
Pantai Tongkaina dan pantai Talawaan Bajo, Sulawesi Utara (Djaguna et al., 2019), beberapa pantai barat-selatan Aceh (Fitria et al., 2019), wilayah utara Taiwan (Kuo dan Huang, 2014), Pantai Adriatic, Italia (Munari et al., 2016) dan masih banyak yang lainnya.

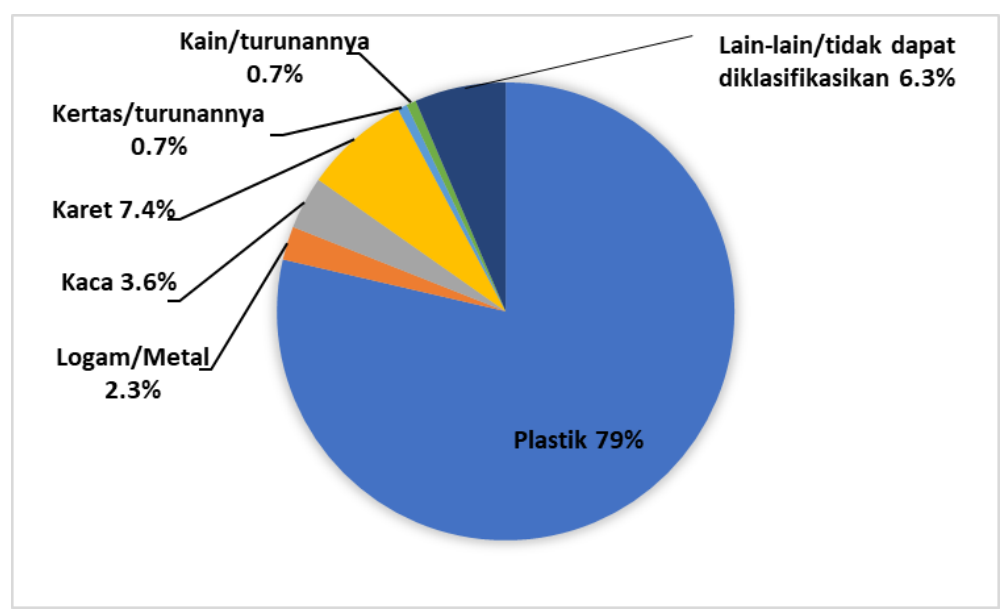

Gambar 3. Komposisi sampah laut di Pantai Kuala Batu

Penyebab tingginya keberadaan sampah plastik adalah karena plastik digunakan hampir pada semua kegiatan manusia dan presistensinya berlangsung dalam jangka waktu yang lama di lingkungan laut (Derraik, 2002). Sampah laut berbahan dasar plastik yang paling banyak ditemukan selama penelitian adalah kantong plastik, plastik kemasan makanan, botol minuman, tutup botol, potongan jaring (alat tangkap ikan) dan tali pancing. Penggunaan barang berbahan plastik sekali pakai seperti kantong plastik sebaiknya dibatasi melalui peraturan daerah dan pemerintah untuk menekan pencemaran laut yang disebabkan oleh plastik. Beberapa negara telah menerapkan pembatasan penggunaan kantong plastik untuk mengurangi polusi, seperti Italia (Munari et al., 2015), Slovenia (Langlbauer et al., 2014) dan Taiwan (Liu et al., 2013).

\section{Sumber Sampah Laut}

Berdasarkan hasil penelitian ini, dapat diketahui bahwa sampah laut di pantai ini berasal dari kegiatan rekreasi dan aktivitas pantai (79\%), medis/personal hygiene (10\%), lain-lain (5\%), aktivitas merokok dan sejenisnya (4\%), serta aktivitas pembuangan dan aktivitas laut/jalur laut masing-masing sebesar 1\%. Menurut Munari et al. (2015), dengan mengetahui jenis dan sumber sampah laut yang terdapat di pantai merupakan hal penting untuk menentukan aksi yang 
bertujuan meminimalkan keberadaannya di lingkungan. Hasil penelitian ini menunjukkan bahwa sumber sampah laut tertinggi di pantai ini adalah bersumber dari kegiatan rekreasi dan aktivitas pantai. Kegiatan rekreasi dan aktivitas pantai menghasilkan sampah sebanyak 79\% dari total sampah yang terdapat di Pantai Kuala Batu. Aktivitas pantai disini meliputi kegiatan memancing yang dilakukan di daerah pantai oleh masyarakat sebagai salah satu kegiatan untuk menyalurkan hobi. Hal ini memang tidak mengherankan, mengingat lokasi pantai ini memang berdekatan dengan pantai-pantai rekreasi yang selalu ramai seperti Pantai Jilbab dan Pantai Bali di Kecamatan Susoh. Hasil penelitian yang dilakukan oleh Zou et al. (2011) di Laut Cina Selatan, menunjukkan bahwa sampah laut yang terdapat di wilayah tersebut, sebanyak 95\% bersumber dari daratan (land-based sourced) melalui kegiatan rekreasi dan akvitas pantai sebagai akibat dari kegiatan manusia.

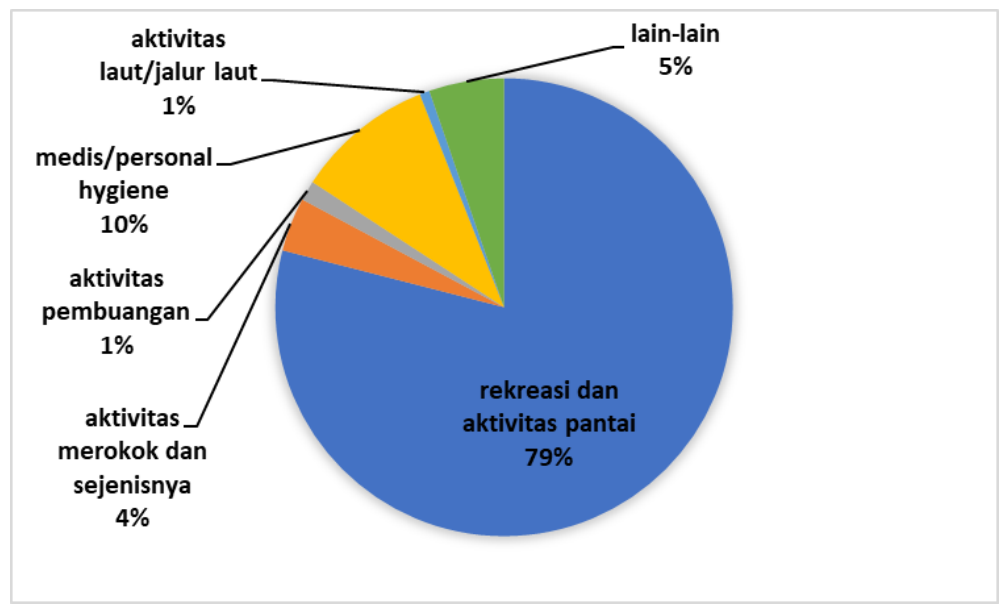

Gambar 4. Sumber sampah laut di Pantai Kuala Batu

Pada umumnya, wisatawan atau pengunjung yang datang ke Pantai Kuala Batu, membawa sendiri makanan dan perlengkapan lainnya. Namun, karena peraturan yang lemah, tidak disediakannya tempat sampah yang memadai serta kurangnya kesadaran lingkungan membuat sampah tidak terkelola dengan baik. Selanjutnya, barang-barang medis dan kebersihan pribadi (personal hygiene) merupakan sumber sampah laut terbanyak kedua yaitu sebesar 10\%, setelah rekreasi dan aktivitas pantai. Selama penelitian, ditemukan berbagai barang medis dan kebersihan pribadi seperti popok bayi, kemasan obat-obatan, kemasan sampo dan sabun. 
Diperkirakan sampah-sampah tersebut berasal dari sungai yang melewati pemukiman padat penduduk di sekitar pantai dan bermuara ke laut.

\section{KESIMPULAN DAN SARAN}

Sampah plastik masih merupakan jenis sampah laut yang mendominasi pada Pantai Kuala Batu yaitu 79\% dari total sampah yang tercatat. Kegiatan rekreasi dan aktivitas pantai merupakan penyebab utama dari sampah laut yang terdapat di pantai ini. Data sampah laut berupa data kelimpahan, komposisi dan sumber sampah laut ini dapat dijadikan referensi dalam menentukan arah kebijakan pemerintah, strategi mitigasi dan rencana aksi yang diperlukan untuk menyelesaikan masalah sampah laut di Aceh.

\section{UCAPAN TERIMA KASIH}

Ucapan terima kasih peneliti kepada berbagai pihak yang telah banyak membantu terlaksananya penelitian ini yaitu mahasiswa dan mahasiswi Universitas Teuku Umar, Fakultas Perikanan dan Ilmu Kelautan, Program Studi Akuakultur (Aulia, Sudirman dan Amalia), Program Studi Perikanan (Darsa dan Ilham) serta Program Studi Sumber Daya Akuatik (Marhaban).

\section{DAFTAR PUSTAKA}

Assuyuti, Y.M., Reza, B.Z., Muhammad, A.T., Azkiya, B., and Pangestuti, U. 2018. "Distribusi dan jenis sampah laut serta hubungannya terhadap ekosistem terumbu karang Pulau Pramuka, Panggang, Air, dan Kotok Besar di Kepulauan Seribu Jakarta". Majalah Ilmiah Biologi Biosfera : A Scientific Journal, 35(2): 91-102.

Barnes, D.K.A., Galgani, F., Thompson, R.C., and Barlaz, M. 2009. "Accumulation and fragmentation of plastic debris in global environments". Philosophical Transactions the Royal Society Publishing, 364: 1985-1998.

Corcoran, P.L., Biesinger, M.C., and Grifi, M. 2009. "Plastics and beaches: a degrading relationship". Marine Pollution Bulletin, 58: 80-84.

Derraik, J.G.B. 2002. "The pollution of the marine environment by plastic debris: A review". Marine Pollution Bulletin, 44(9):842-52. 
Djaguna, A., Wilmy, E. Pelle., Joshian, N.W.S., Hermanto, W.K.M., Natalie, D.C.R., and Erwin, L.A.N. 2019. "Identifikasi sampah laut di pantai tongkaina dan talawaan bajo". Jurnal Pesisir dan Laut Tropis, 7(3): 174-182.

FAO. 2017. Microplastics in Fisheries and Aquaculture: Status of Knowledge on Their Occurrence And Implications for Aquatic Organisms and Food Safety. Rome: Food and Agriculture Organization.

Fitria, R., Diana, F., Riani, E., Yulianto G., and Najmi, N. 2019. "Analysis of sources and composition of marine debris in western and southern Aceh, Indonesia". IOP Conf. Series: Earth and Environmental Science, 404: 1-7.

Hardesty, B.D., Lawso, T.J., Tonya, V. D.V., Matt, L., and Chris, W. 2016. "Estimating quantities and sources of marine debris at a continental scale". Frontiers in Ecology and the Environment, 15 (1): 18-25.

Kuo, F.J., and Huang, H.W. 2014. "Strategy for mitigation of marine debris: analysis of sources and composition of marine debris in northern Taiwan". Marine Pollution Bulletin, 83: 7078.

Laglbauer, B.J.L., Melo, F. R., Andreu-Cazenave, M., Brunelli, L., Papadatou, M., Palatinus, A., Grego, M., Deprez, T. 2014. "Macrodebris and microplastics from beaches in Slovenia". Marine Pollution Bulletin, 89: 356-366.

Law, K.L., Morét-Ferguson. S., and Maximenko, N.A. 2010. "Plastic accumulation in the north atlantic subtropical gyre". Science, 329: 1185-88.

Liu, T.-K., Wang, M.W., Chen, P.. 2013. "Influence of waste management policy on the characteristics of beach litter in Kaohsiung, Taiwan”. Marine Pollution Bulletin, 72:99106.

Munari, C., Corinne, C., Umberto, S., and Michele, M. 2016. "Marine litter on Mediterranean shores: Analysis of composition, spatial distribution and sources in north-western Adriatic beaches". Waste Management, 49:483-490.

Opfer, S., Courtney, A., and Sherry, L. 2012. NOAA Marine Debris Shoreline Survey Field Guide NOAA Marine Debris Program. USA: Silver Spring. 
Pawar, P.R., Sanket, S.S., and Rahul, B.P. 2016. "Plastic marine debris: sources, distribution and impacts on coastal and ocean biodiversity". Proceedings of the Royal Society: Biological Sciences, 3:54-40.

Ramirez-Llodra, E., Company, J.B., Sarda` F., De Mol, B., Coll, M. 2013. "Effects of Natural and Anthropogenic Processes in the Distribution of Marine Litter in the Deep Mediterranean Sea". Progress in Oceanography, 118: 273-287.

Rochman, C.M., Akbar, T., Susan, L.W., Dolores, V.B., Rosalyn, L., Jeffrey, T.M., Foo-Ching, T., Shinta, W., and Swee, J.T. 2015. "Anthropogenic debris in seafood: plastic debris and fibers from textiles in fish and bivalves sold for human consumption". Scientific Report, 5:1-10.

Shuker., Iain, G., Cadman., Anne, C. 2018. Indonesia-Marine debris hotspot rapid assessment: synthesis report (English) Marine Debris Hotspot Rapid Assessment (Synthesis Report). Washington: World Bank Group.

The Ocean Conservancy. 2010. Trash Travell From Our Hands to the Sea, Around the Globe, and Through Time. Washington: Conservation International.

Zhou, P., Chuguang, H., Hongda, F., Weixu, C., Dongmei, L., Xiaomin, L., Hansheng, Y. 2011 "The abundance, composition and sources of marine debris in coastal seawaters or beaches around the northern South China Sea (China)". Marine Pollution Bulletin, 62(9) :19982007. 